\title{
Multi-instrument observations of the ionospheric counterpart of a bursty bulk flow in the near-Earth plasma sheet
}

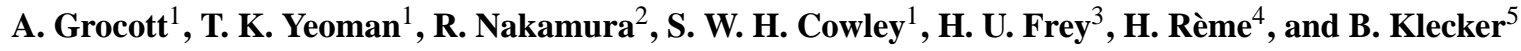 \\ ${ }^{1}$ Department of Physics and Astronomy, University of Leicester, Leicester LE1 7RH, UK \\ ${ }^{2}$ Space Research Institute, Austrian Academy of Sciences, Schmiedlstr. 6, 8042 Graz, Austria \\ ${ }^{3}$ Space Sciences Laboratory, University of California Berkeley, Berkeley, CA 94720, USA \\ ${ }^{4}$ CESR/CNRS, 9 Avenue du Colonel Roche, B. P. 4346, F-31028 Toulouse Cedex 4, France \\ ${ }^{5}$ MPI für Extraterrestrische Physik, Giessenbachstrasse, D-85748 Garching, Germany
}

Received: 21 March 2003 - Revised: 11 July 2003 - Accepted: 22 August 2003 - Published: 2 April 2004

\begin{abstract}
On 07 September 2001 the Cluster spacecraft observed a "bursty bulk flow" event in the near-Earth central plasma sheet. This paper presents a detailed study of the coincident ground-based observations and attempts to place them within a simple physical framework. The event in question occurs at $\sim 22: 30 \mathrm{UT}$, some $10 \mathrm{~min}$ after a southward turning of the IMF. IMAGE and SAMNET magnetometer measurements of the ground magnetic field reveal perturbations of a few tens of $\mathrm{nT}$ and small amplitude Pi2 pulsations. CUTLASS radar observations of ionospheric plasma convection show enhanced flows out of the polar cap near midnight, accompanied by an elevated transpolar voltage. Optical data from the IMAGE satellite also show that there is a transient, localised $\sim 1 \mathrm{kR}$ brightening in the UV aurora. These observations are consistent with the earthward transport of plasma in the tail, but also indicate the absence of a typical "large-scale" substorm current wedge. An analysis of the field-aligned current system implied by the radar measurements does suggest the existence of a small-scale current "wedgelet", but one which lacks the global scale and high conductivities observed during substorm expansions.
\end{abstract}

Key words. Ionosphere (auroral ionosphere; ionospheremagnetosphere interactions; plasma convection)

\section{Introduction}

A major goal of solar-terrestrial physics is to improve the understanding of the nature of the coupled magnetosphereionosphere system. This is increasingly being achieved using simultaneous ground- and space-based observations which are becoming ever more available. On the dayside, spacecraft observations of impulsive magnetopause reconnection, or flux transfer events (FTEs), have been linked to consequent flow and auroral features in the ionosphere (e.g. Lockwood et al., 1989, 1993; Elphic et al., 1990; Pinnock et al.,

Correspondence to: A. Grocott

(ag27@ion.le.ac.uk)
1993, 1995; Moen et al., 1995; Provan et al., 1998; Neudegg et al., 1999, 2000; Milan et al., 2000). Correspondingly on the nightside, magnetospheric substorms have been studied to great depths in terms of their large-scale ramifications on the magnetic tail and nightside ionosphere (e.g. Russell and McPherron, 1973; Hones, 1979; Baker et al., 1996; Lui, 1996; Opgenoorth and Pellinen, 1998; Grocott et al., 2000, 2002). However, substorms are not the only mechanism by which the tail contributes to magnetosphere-ionosphere coupling. For example, Huang et al. (2001) reported observations of quasi-sinusoidal nightside flow oscillations in $\mathrm{Su}-$ perDARN radar data during an extended interval of modest northward IMF, which were associated with the formation of large-scale clockwise flow vortices in the post-midnight sector. The authors associate these flows with global oscillations of an essentially closed tail. Walker et al. (1998, 2002), on the other hand, have reported the occurrence of latitudinally-restricted $\left(\sim 1^{\circ}\right.$ north-south) bursts of highspeed $\left(\sim 2 \mathrm{~km} \mathrm{~s}^{-1}\right)$ westward flow in the pre-midnight sector under similar interplanetary conditions (weak IMF with small clock angle). Walker et al. interpreted the bursts as being due to sporadic energy release and field dipolarisation in the geomagnetic tail associated with a viscously-driven twin-vortex flow system. Recently, Grocott et al. (2003) have found intervals of northward IMF during which fast $\left(\sim 1000 \mathrm{~m} \mathrm{~s}^{-1}\right)$ flow bursts lasting a few tens of minutes are observed in the nightside ionosphere. These bursts were not accompanied by any classic substorm phenomena, such as auroral enhancements, particle injections or magnetic bays, yet were shown to be associated with field reconfiguration after reconnection in the tail.

One further class of phenomena, which have been observed during all phases of the substorm cycle, are narrow channels of fast flow in the central plasma sheet known as bursty bulk flows (BBFs) (Baumjohann et al., 1990; Angelopoulos at al., 1992). These azimuthally-localised flows in the near-Earth plasma sheet have been associated with numerous counterpart signatures in the ionosphere. De la Beaujardière et al. (1994) report the occurrence of bursts 
of equatorward-directed flow in nightside Sondrestrom radar data, which take place during a "quiet-time" interval in which the transverse components of the IMF were small and directed mainly northward. These flow bursts were initiated near the nightside open-closed field line boundary, had amplitudes up to several $100 \mathrm{~m} \mathrm{~s}^{-1}$, and recurred at $\sim 1 \mathrm{~h}$ intervals, lasting on each occasion for a few tens of minutes. Simultaneous auroral data show that each flow pulse was accompanied by an activation of the poleward-most arc system, in which a new east-west aligned arc formed poleward of the existing boundary, and subsequently moved equatorward, together with existing precipitation structures. This behaviour strongly suggests an origin in bursts of reconnection in the "quiet-time" tail. Poleward boundary auroral intensifications (PBIs) and arc "bifurcations" have subsequently been shown to occur commonly under a wide variety of conditions, both during "quiet" times, and in the growth, expansion and recovery phases of substorms (Lyons et al., 1999), often leading to the ejection of one or more north-south aligned auroral forms (called "auroral streamers") towards lower latitudes (Henderson et al., 1998).

Other examples of ionospheric flow excitation in connection with BBFs have been reported, as well as associated relatively weak structured magnetic disturbances and Pi2 signals. Sergeev et al. (1990) discussed STARE radar observations of fast $\left(\sim 1000 \mathrm{~m} \mathrm{~s}^{-1}\right)$ equatorward flows which coincided with ISEE-1 and -2 spacecraft measurements of enhanced central plasma sheet earthward convection. These observations occurred during periods of prolonged, steady convection without any apparent classic substorm activity. The observed features are, therefore, interpreted as the result of impulsive reconnection enhancements in the distant tail. In another study, Yeoman and Lühr (1997) interpreted pulses of ionospheric flow seen in the CUTLASS radars as signatures of ionospheric current vortices associated with pairs of field aligned currents. Yeoman et al. (1998) went on to relate these effects to transient features in Geotail field and plasma data which are suggested to be produced by BBFs. More recently, Kauristie et al. (2000) have conducted a superposed epoch analysis of Wind satellite plasma data and ionospheric conjugate magnetic field observations. This study provides evidence for an association between transient plasma sheet flows and vortex-like ground magnetic field variations.

A review of current understanding of these various related phenomena is given by Amm and Kauristie (2002). One major question they pose concerns the difference between substorm and non-substorm events, and this will be discussed further below. They also point out, however, that many of the observed ionospheric effects can be shielded or greatly obscured during substorm expansions, by the inherent largescale electrodynamics. In the present study, we investigate the ionospheric counterpart of a BBF which occurred during a substorm growth phase, thus largely circumventing any such effects. Excellent ground-based data are available for the event, which occurred on 7 September 2001, allowing flow, geomagnetic field, and auroral phenomena to be examined. The Cluster spacecraft provide plasma and field data in the near-Earth plasma sheet, with conjugate ionospheric observations being provided by the CUTLASS radars, the IMAGE and SAMNET magnetometers and the FUV auroral imager on the IMAGE spacecraft (see Sect. 2 for details of this instrumentation). During the event, ground magnetic activity was low (consistent with no substorm activity) with perturbations of magnitude $\sim 30 \mathrm{nT}$ being typically observed. Nevertheless, significant ionospheric flow and auroral signatures were observed and these are considered below, along with a discussion of potential driving mechanisms and their implications for our understanding of substorm physics.

\section{Instrumentation}

As discussed above, this study combines simultaneous measurements from a number of sources to investigate the flow, magnetic, and auroral signatures associated with a BBF event on 7 September 2001. Ionospheric convection velocities are provided primarily by the Pykkvibær radar of the Cooperative UK Twin-Located Auroral Sounding System (CUTLASS). CUTLASS forms part of the Super Dual Auroral Radar Network (SuperDARN), an international array of HF coherent radars spanning the auroral regions of both the Northern and Southern Hemispheres (Greenwald et al., 1995). Data from the entire northern hemisphere SuperDARN network, which consisted of eight radars during the interval being studied, is also used to provide a global solution to the ionospheric electric potential, and hence, the global convection pattern. This is achieved using the Map Potential Model (Ruohoniemi and Baker, 1998) which fits the line-of-sight SuperDARN data to an 8th order expansion (in this case) of the electrostatic potential in spherical harmonics. Information from the statistical model of Ruohoniemi and Greenwald (1996), parameterised by IMF conditions, is used to stabilise the solution in regions where no measurements are available. During the study interval, all eight radars were operating in a standard mode, in which each radar scans through 16 beams of azimuthal separation $3.24^{\circ}$, with a total scan time of $2 \mathrm{~min}$. Each beam is divided into 75 range gates of length $45 \mathrm{~km}$, and so in each full scan the radar covers $52^{\circ}$ in azimuth and over $3000 \mathrm{~km}$ in range, an area of over $4 \times 10^{6} \mathrm{~km}^{2}$.

The fields-of-view of the CUTLASS radar pair are illustrated in the top panel of Fig. 1, which shows a geographic projection from the pole to $\sim 60^{\circ}$ latitude and from $-90^{\circ}$ through to $90^{\circ}$ longitude. Beam 10 of the CUTLASS Iceland radar is indicated by the dashed line. Also shown on the figure are the locations of four magnetometers from the International Monitor for Auroral Geomagnetic Effects (IMAGE) array (Lühr et al., 1998) (JAN, BJN, NAL, and KIR), and one from the Sub-Auroral Magnetometer Network (SAMNET) (Yeoman et al., 1990) (HLL). The solid black curves on the figure represent the footprint of the Cluster (1) spacecraft between 22:00 and 00:00 UT, mapped into the ionosphere using the T-96 magnetic field model (Tsyganenko, 1995), with $B_{Z}=+2$ (upper curve) and $B_{Z}=-5$ (lower curve). These two 

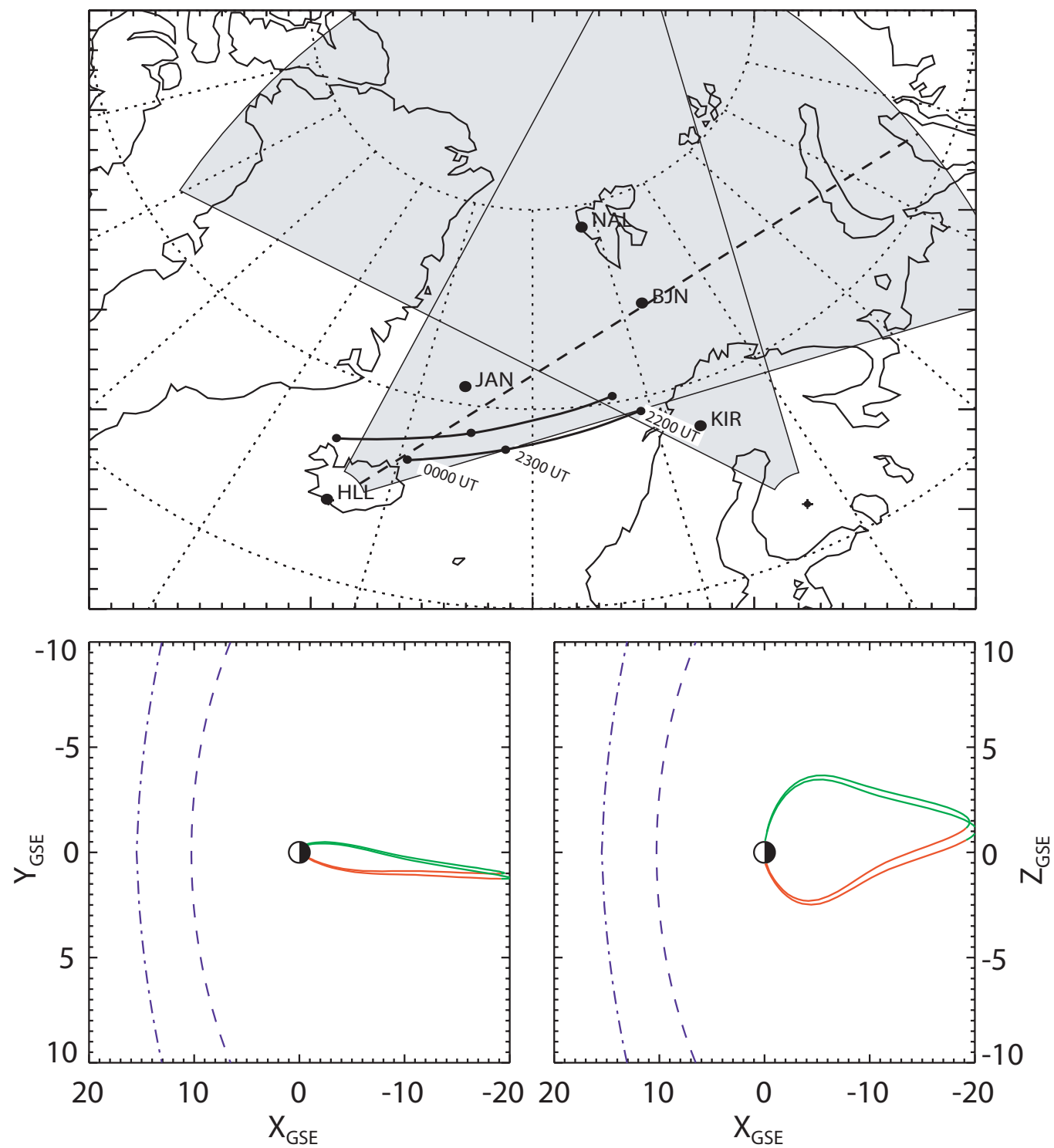

Fig. 1. The fields-of-view of the CUTLASS radar pair shown on a geographic projection from the pole to $\sim 60^{\circ}$ latitude and from $-90^{\circ}$ through to $90^{\circ}$ longitude. Also indicated are the locations of four magnetometers from the IMAGE array (JAN, BJN, NAL, and KIR) and one from the SAMNET array (HLL). The solid black curves represent the footprint of the Cluster (1) spacecraft between 22:00 and 00:00 UT, mapped into the ionosphere using the T-96 magnetic field model with $B_{Z}=+2$ (upper curve) and $B_{Z}=-5$ (lower curve). The bottom two panels show the Cluster field lines at 22:00 UT (upper field line in both panels) and 23:00 UT in the $X-Y$ and $X-Z$ GSE planes. Indicated by the dashed and dot-dashed curves are a nominal magnetopause and bow shock, respectively.

curves give an indication of the uncertainty in the mapped location of the Cluster footprint given the variation in IMF orientation over the interval (see below). The bottom two panels of Fig. 1 show the Cluster field lines at 22:00 UT (upper field line in both panels) and at 23:00 UT (lower field line) in the $X-Y$ and $X-Z$ GSE planes. Indicated on these panels by the dashed and dot-dashed curves is a nominal magnetopause and bow shock, respectively. At the time of the BBF event studied here, the Cluster spacecraft were located at approximately $(X, Y, Z)_{\mathrm{GSE}}=(-20,0,0) R_{E}$ (the spacecraft separation was of the order of $\sim 2000 \mathrm{~km}$, discussed in more detail below). The Composition and Distribution Function Analyzer (CODIF) sensor of the Cluster Ion Spectrometry (CIS) instrument (Rème et al., 2001) provides ion velocity data for the event, and magnetic data is provided by the fluxgate magnetometer (FGM) (Balogh et al., 2001), presented here in GSM coordinates.

Data from two further spacecraft have been used in this study. First, the Advanced Composition Explorer (ACE) spacecraft (Stone et al., 1998), located upstream of the Earth at GSM coordinates $(X, Y, Z)=(230,-37,11) R_{E}$, provided interplanetary magnetic field (IMF) data from the 


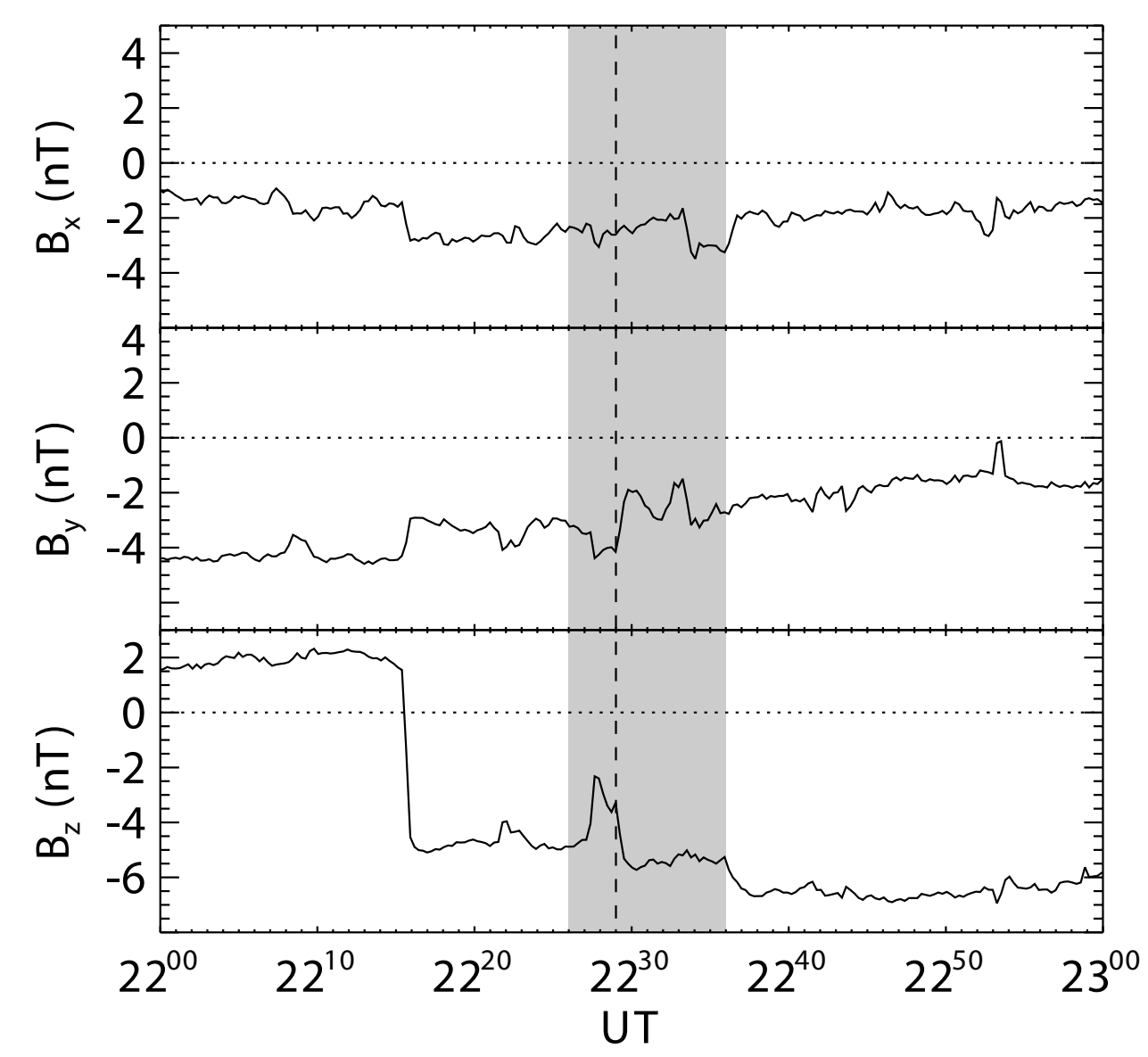

Fig. 2. $B_{x}, B_{y}$, and $B_{z}$ IMF data from the ACE spacecraft magnetometer instrument in GSM coordinates for the interval 22:00-23:00 UT, lagged by $73 \mathrm{~min}$ to account for the propagation delay of field changes from ACE to the dayside ionosphere. The grey shaded portion represents the interval 22:26-22:36 UT corresponding to the interval of Cluster data show in Fig. 3. The vertical dashed line at 22:29 UT indicates the time of a BBF event identified in the Cluster data.

magnetometer (MAG) instrument (Smith et al., 1999) and solar wind data from the Solar Wind Electron Proton Alpha Monitor (SWEPAM) instrument (McComas et al., 1998). Second, the Spectrographic Imager (SI) on board the Imager for Magnetopause-to-Aurora Global Exploration (IMAGE) spacecraft (Mende et al., 2000a, b) provided images of the aurora during the interval. This instrument viewed the whole of the northern polar ionosphere during the course of the interval, and provided images approximately every $2 \mathrm{~min}$. These consist of 5-s integrations of UV photons at a wavelength of $135.6 \mathrm{~nm}$.

\section{Observations}

\subsection{Upstream interplanetary magnetic field observations}

Figure 2 presents data from the ACE spacecraft magnetometer instrument in GSM coordinates for the interval 22:00-23:00 UT on 7 September 2001. It should be noted that the propagation delay of field changes from ACE to the dayside ionosphere, estimated following the method of
Khan and Cowley (1999) to be $73 \pm 2 \mathrm{~min}$ (using a value of $V_{S W} \sim 367 \pm 10 \mathrm{~km} \mathrm{~s}^{-1}$ ), has been used to lag the data displayed here. The grey shaded portion of this figure represents the interval 22:26-22:36 UT, corresponding to the interval of Cluster data shown in Fig. 3, discussed in the next section. The vertical dashed line at 22:29 UT indicates the time of a BBF event identified in the Cluster data. The top panel shows the $B_{X}$ component of the magnetic field, which remained relatively steady between about -1 and $-3 \mathrm{nT}$ during the entire interval. The middle panel shows the $B_{Y}$ component, which shows a fairly sudden increase from $\sim-4 \mathrm{nT}$ before the BBF to $\sim-2 \mathrm{nT}$ after. The bottom panel shows the $B_{Z}$ component. This dropped suddenly from $\sim+2 \mathrm{nT}$ to $\sim-5 \mathrm{nT}$ at $\sim 22: 16 \mathrm{UT}$, and then briefly increased to $\sim-2 \mathrm{nT}$ at $\sim 22: 27$ UT, before dropping back down to $\sim-6 \mathrm{nT}$ at the time of the BBF where it remained for the rest of the interval. It is the change from a northward to a southward IMF orientation that would eventually give rise to the equatorward shift in the mapped location of the Cluster footprint (mentioned above). However, the actual change in footprint location between 22:16 UT and the time of the BBF just 10-15 min later 


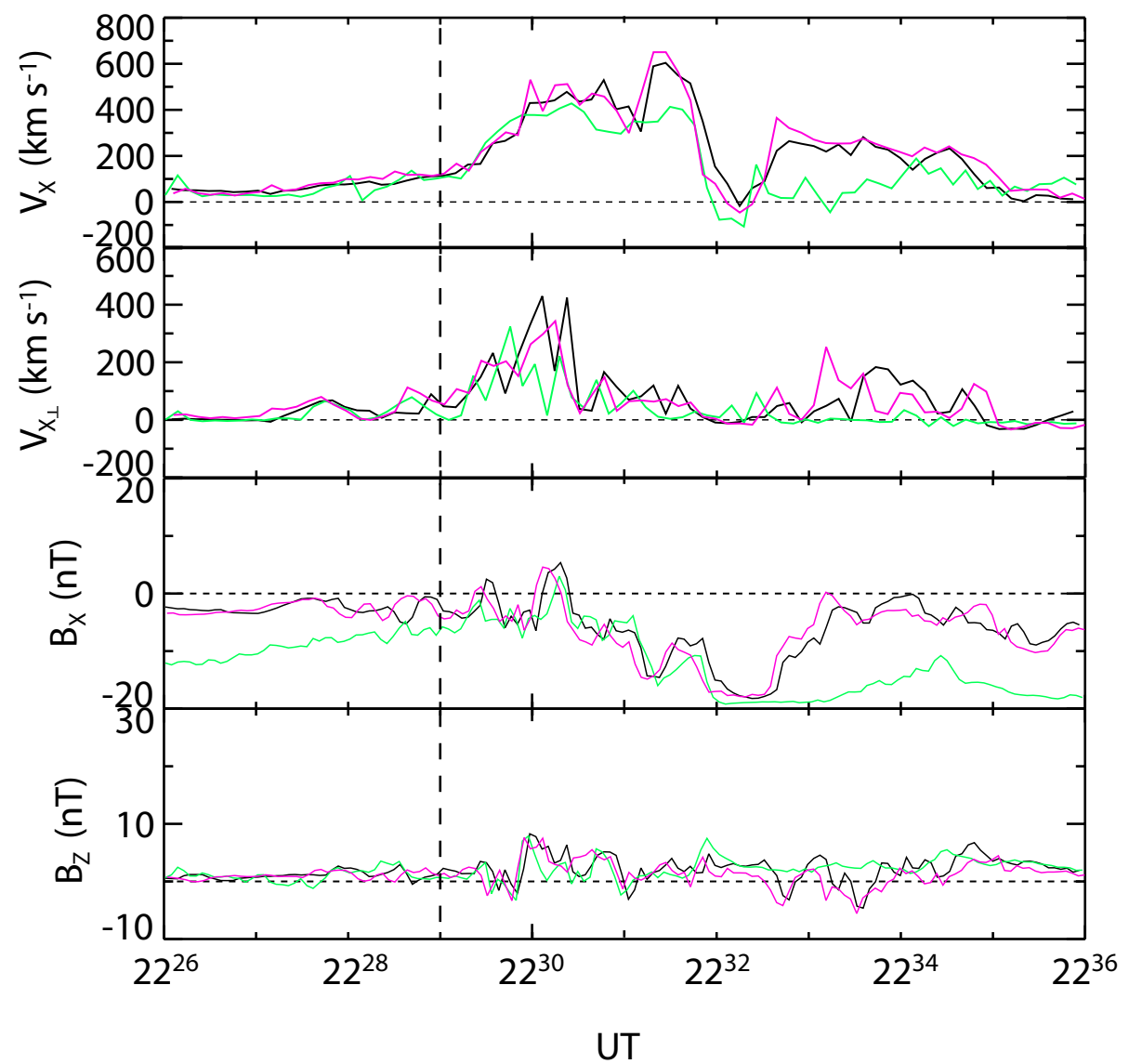

Fig. 3. A summary of Cluster flow and magnetic observations for the interval 22:26-22:36 UT, presented in GSM coordinates. The top panel shows the $V_{x}$ component of the flow and the second panel shows the magnetic field-perpendicular component of this flow. The bottom two panels show the $B_{x}$ and $B_{z}$ components of the magnetic field. These data have been used to estimate an "onset" time for the BBF of 22:29 UT, which is indicated on this and other plots by the vertical dashed line.

is likely to be smaller than the extremes indicated on Fig. 1, and certainly not significant enough to affect the conclusions of this study.

\subsection{Cluster CIS / FGM observations}

As the present paper is primarily concerned with ionospheric observations we therefore provide only a summary of the flow and magnetic data from Cluster. This is presented in Fig. 3 for the interval 22:26-22:36 UT. Data are shown for the Cluster 1 spacecraft (black), Cluster 3 (green) and Cluster 4 (magenta) (the CIS instrument on Cluster 2 failed and so data from this spacecraft are not discussed). During the interval the four spacecraft formed an inverted tetrahedron with Cluster 1,2 , and 4 in approximately the same $X-Y$ plane, and Cluster 3 about $2000 \mathrm{~km}$ lower in $Z$. In the top panel of Fig. 3 GSM $X$-component velocity data $\left(V_{X}\right)$ reveal a large $\left(\sim 600 \mathrm{~km} \mathrm{~s}^{-1}\right)$ earthward flow signature during the interval 22:28-22:35 UT. The second panel shows the component of this flow which is perpendicular to the magnetic field $\left(V_{X \perp}\right)$. These data reveal perpendicular flows of $\sim 200-400 \mathrm{~km} \mathrm{~s}^{-1}$, which are enhanced above the Baumjohann et al. (1989) average convection velocity
$\left(\mathrm{V}_{\mathrm{c}}(\mathrm{AE})<100 \mathrm{~km} \mathrm{~s}^{-1}\right.$ for $\left.\mathrm{AE}<200 \mathrm{nT}\right)$ by a few times. It is this signature, and the accompanying small $(\sim 10 \mathrm{nT})$ enhancement in $B_{Z}$ (bottom panel), which are evidence of field dipolarisation and the earthward transport of flux and hence, the occurrence of a BBF (Angelopoulos et al., 1992). Nakamura et al. (2001) report a peak flux transport rate of the order of $2 \mathrm{mV} \mathrm{m}^{-1}$ for BBFs, which is also consistent with field-perpendicular flows of this magnitude. For our purposes, these data have been used to identify the BBF and estimate an "onset" time of 22:29 UT, which is indicated on this and other plots by the vertical dashed line. It should be noted that the earthward flow seen in $V_{X \perp}$ is still present when Cluster 1 and 4 re-enter the central plasma sheet at $\sim 22: 33$ UT (evidenced by the decrease in (negative) $B_{X}$ back to near zero (third panel)). The flows persist, albeit somewhat less intensely, until $\sim 22: 35$ UT, after which time they die away.

\subsection{Ground-based and auroral observations}

This section looks closely at the ground magnetic, ionospheric flow, and auroral data during the hour surrounding the identification of the BBF at Cluster. Presented in Fig. 4 

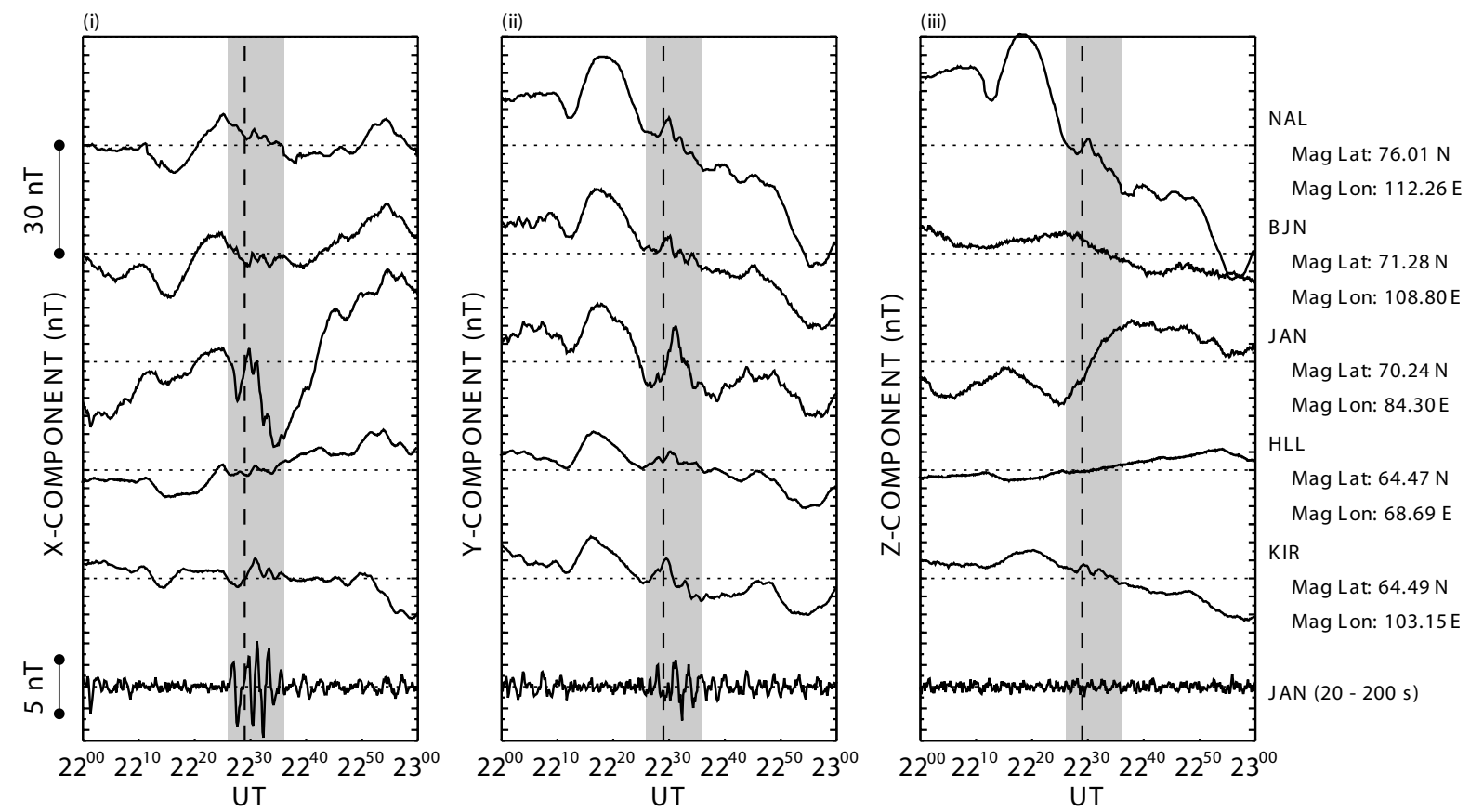

Fig. 4. $X-Y$ - and $Z$-component magnetometer data from the five stations indicated in Fig. 1, for the interval 22:00-23:00 UT. The vertical dashed line and grey shaded area are as in Fig. 2, and the scale of the curves is shown on the left-hand side of the figure. The bottom curves show Pi2 filtered data (20-200s) from the JAN magnetometer, and have a separate scale as indicated. Station identifier codes and their locations are indicated on the right-hand side.

are $X-Y$ - and $Z$-component magnetometer data from the five stations indicated in Fig. 1, for the interval 22:00-23:00 UT. The vertical dashed line and grey shaded area are as in Fig. 2, and the scale of the curves is shown on the left-hand side of the figure. The bottom curves show Pi2 filtered data (20-200 s) from the JAN magnetometer, and have a separate scale as indicated. Looking first at these filtered data, there is a small amplitude Pi2 pulsation nearly coincident with the flow enhancement seen at Cluster. The Pi2 is most prominent in the $X$-component (amplitude $\sim 8 \mathrm{nT}$ ), weaker in the $Y$-component and non-evident in the $Z$-component. Its "onset" is a few minutes before Cluster observed the BBF proper, although there are small amplitude flows and magnetic perturbations in the Cluster data (see Fig. 3) which begin at $\sim 22: 27$ UT, coincident with the Pi2.

Looking at the unfiltered data, the most obvious characteristic to note is the small scale of the perturbations observed during the BBF interval. The largest disturbance over the hour of interest, seen in the $Z$-component by NAL, is $\sim 60 \mathrm{nT}$, with typical values $<30 \mathrm{nT}$. The JAN magnetometer sees the most prominent signature during the BBF itself, and is also the station closest to the mapped location of the Cluster footprint (Fig. 1). This feature at $\sim 22: 30$ UT, which consists of a double peak in the $X$-component and a single peak in the $Y$-component, both of amplitude $\sim 10 \mathrm{nT}$, is also evident on a much smaller scale in the data from the other four magnetometers. In the $Z$-component at JAN we also see a $\sim 30 \mathrm{nT}$ increase over the $\sim 10 \mathrm{~min}$ of the event. HLL (to the west of JAN) also sees a small increase, whereas the more eastern stations see a decrease. It is worth noting that at $\sim$ 23:20 UT a substorm onset is apparent in the magnetometer and auroral data (not shown). This corroborates our classification of this event as being in a substorm growth phase, and is consistent with the southward turn of the IMF approximately $1 \mathrm{~h}$ previously.

The CUTLASS data is introduced in Fig. 5, which shows velocity measurements from beam 10 of the Iceland East radar (marked as a dashed line in Fig. 1), along with $X$-component data from the HLL, JAN, and BJN magnetometers. The top panel shows range-time-velocity flow data from beam 10 of the radar for the interval 22:00-23:00 UT. The colour scale is defined on the right-hand side of the figure, with green-blue indicating flows towards the radar (positive velocities) and yellow-red indicating flows away (negative velocities). Before 22:29 UT, the radar sees relatively low velocities of a few $\sim 100 \mathrm{~m} \mathrm{~s}^{-1}$ (green and yellow). After this time, apparently coincident with the "onset" time of the BBF, the flows developed rapidly, reaching velocities of $500-1000 \mathrm{~m} \mathrm{~s}^{-1}$. In fact, as suggested above, the BBF is likely to have commenced some minutes earlier, perhaps not being detected until $\sim 22: 29$ UT, owing to the location of the Cluster spacecraft. Such timing issues, however, cannot be resolved with the data available during this interval and would be better addressed during events occurring when the Cluster spacecraft separation was much larger. After the main flow burst, CUTLASS observed further enhancements, or changes in the flow, at $\sim 22: 43$ and $\sim 22: 49$ UT. These also correspond to small $\left(<100 \mathrm{~km} \mathrm{~s}^{-1}\right)$ enhancements in the 


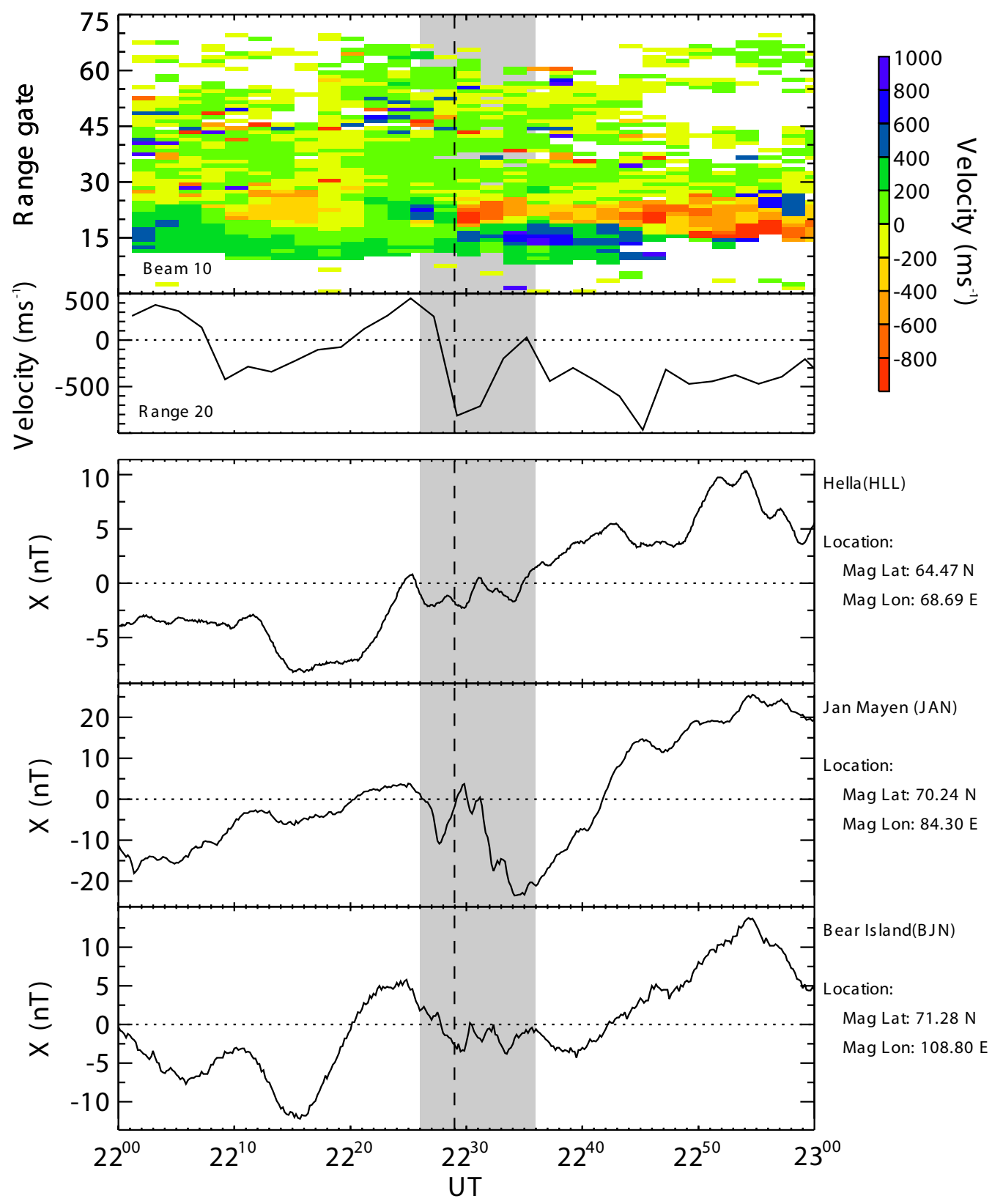

Fig. 5. Range-time-velocity measurements from beam 10 of the Iceland East radar (top panel), a velocity-time profile from range 20 of beam 10 (second panel) and $X$-component data from the HLL, JAN, and BJN magnetometers (bottom three panels) for the interval 22:00-23:00 UT. The vertical dashed line and grey shaded area are as in Fig. 2.

Cluster flow data (not shown), although as isolated signatures they would not constitute additional BBF activity according to the criteria of Angelopoulos et al. (1992). Finally, note that the flows observed by CUTLASS after 22:29 UT are directed both away from the radar (red) and towards the radar (blue). The boundary between the two indicates a flow reversal and is therefore potentially a proxy for the open-closed field line boundary. This boundary appears to move away from the radar (i.e. with a poleward component) up until $\sim 22: 36 \mathrm{UT}$, and then begins to return to nearer ranges. This is considered further in Sect. 4.2, below.
The ionospheric velocity variations discussed above are depicted more quantitatively in the second panel of Fig. 5, which shows a velocity-time profile from range 20 of beam 10. This range gate highlights the large $\left(>1000 \mathrm{~m} \mathrm{~s}^{-1}\right)$ variations and is located close to the location of the JAN magnetometer. Comparing the flow data (which has a considerable east-west component) to the $X$-component of the HLL, JAN, and BJN magnetometer data (shown in the bottom three panels) suggests some possible correlation between the two throughout the interval. 

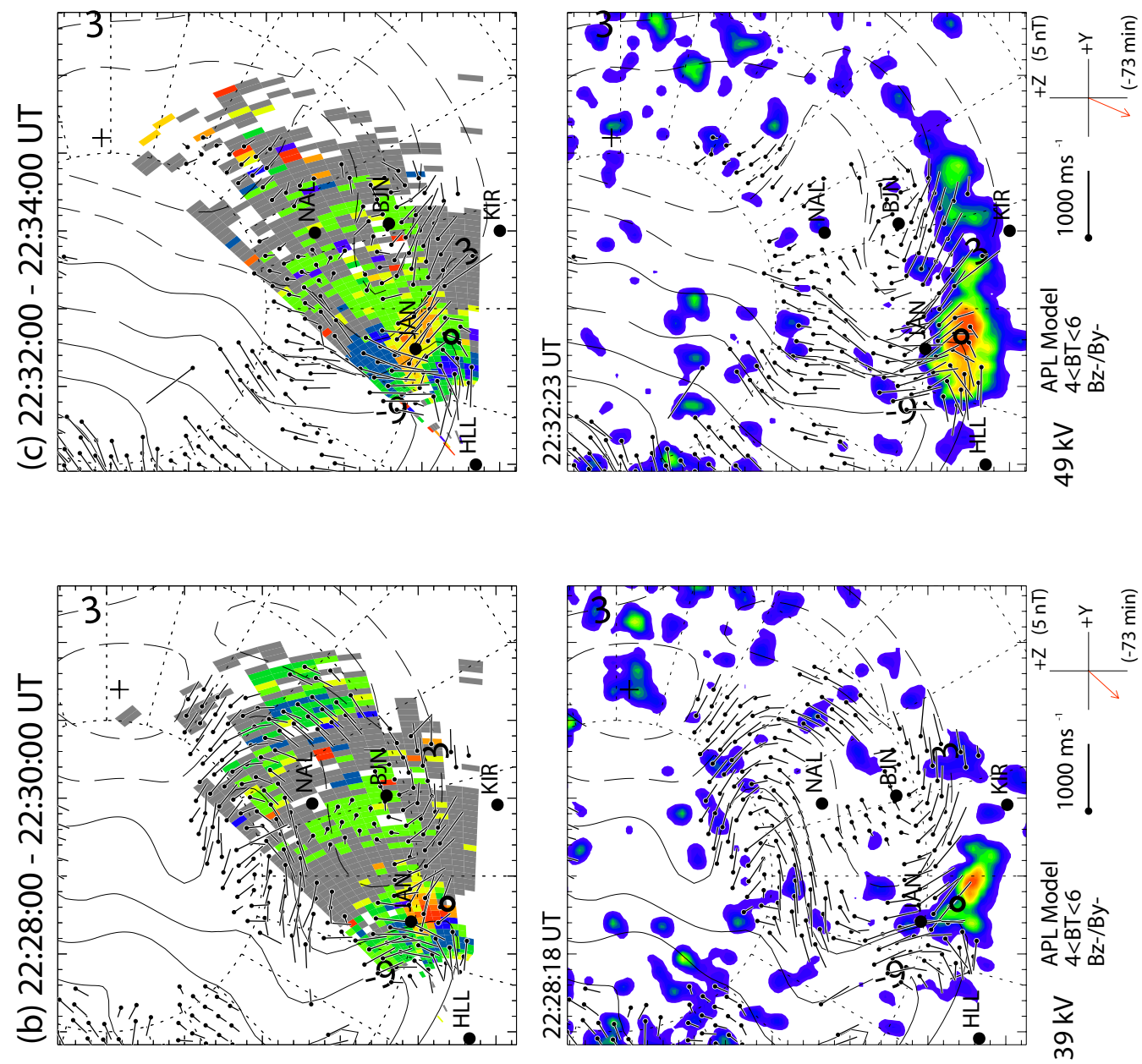

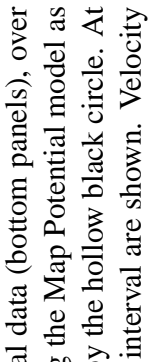

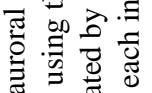
$3 \stackrel{0}{8}: \frac{0}{0}$

屾

宅

芯芯道

吕

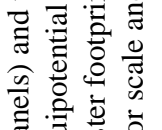

壱芯芯

苍导导

氶竞泀

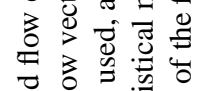

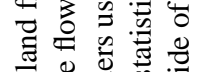

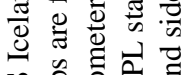
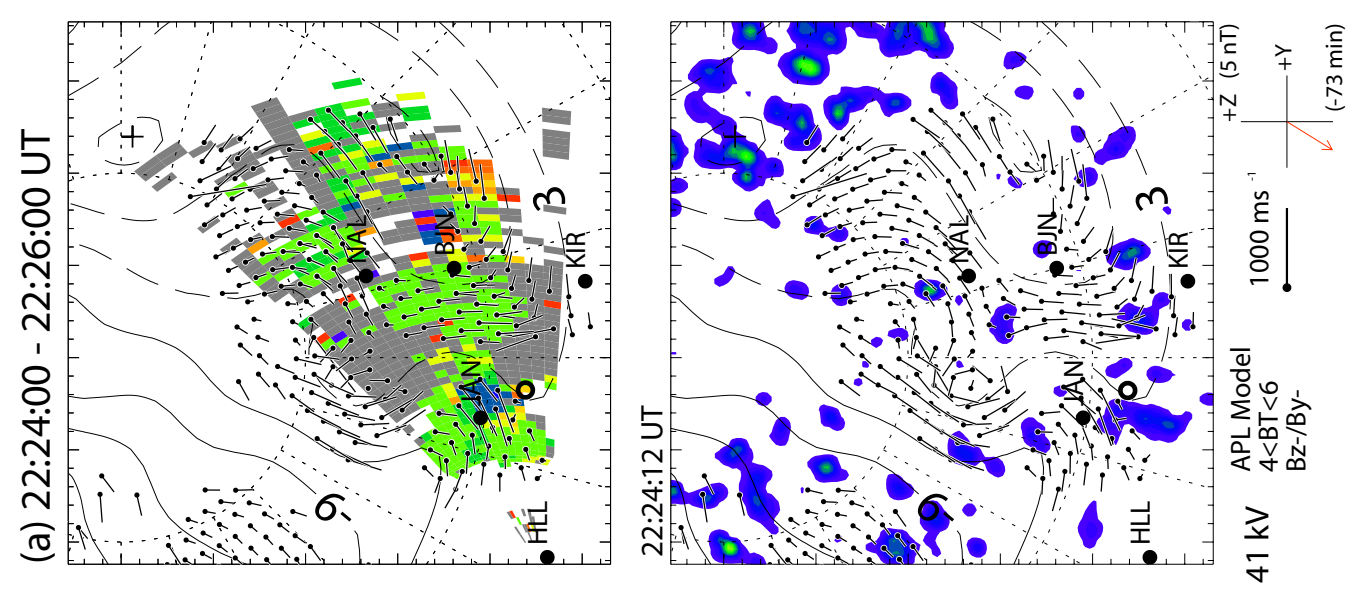

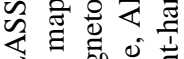

出

乙)

巳ี

पे क्ञ

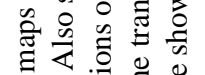

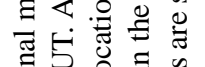

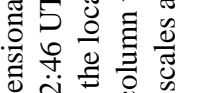

ฮั่

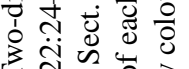

औ ปิ

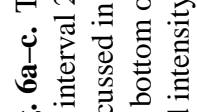

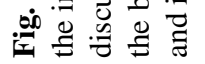



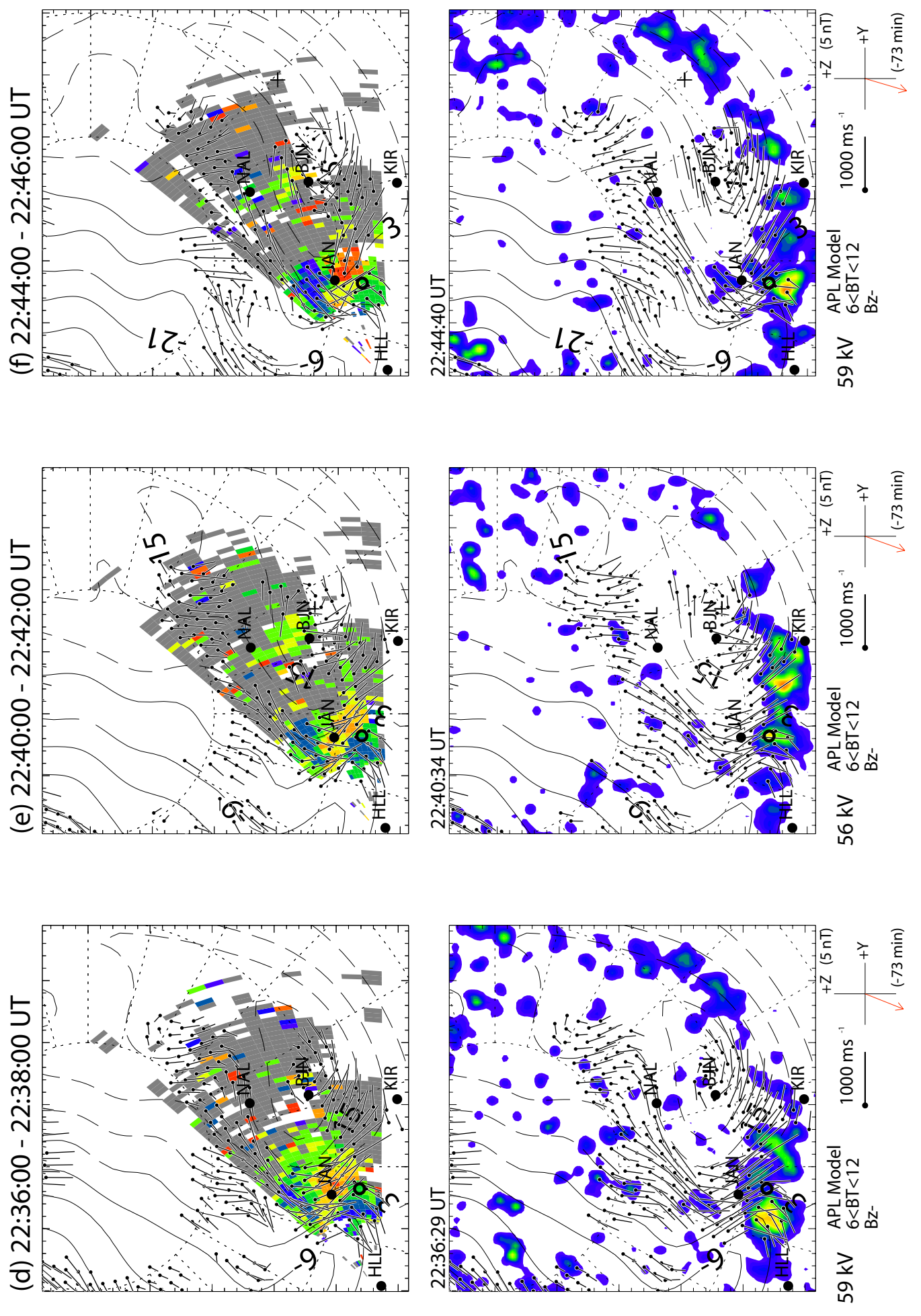

نْ 
If the magnetic perturbations are due to overhead Hall currents, then they should correlate with the flow variations according to $\Delta X \propto \Sigma_{H} V_{W}$, where $\Delta X$ is the northward component of the magnetic perturbation, $V_{W}$ is the westward component of the flow, and $\Sigma_{H}$ is the height-integrated ionospheric Hall conductivity. If we take values of $\sim 1000 \mathrm{~m} \mathrm{~s}^{-1}$ for the flow speed, and magnetic perturbations of $\sim 10 \mathrm{nT}$, then the implied value of $\Sigma_{H}$ is small, of the order of $0.1 \mathrm{~S}$. This is likely to have contributed to the relatively unperturbed nature of the ionospheric flow pattern, whereas regions of high conductivity (e.g. during the substorm expansion phase onset) can often result in flow diversion and suppression (e.g. Yeoman et al., 2000). It may also explain their being no dropout of ionospheric backscatter observed by CUTLASS, since regions of high conductivity are often associated with precipitation-induced D-region radio absorption (Milan et al., 1996).

To better visualise the flow data, 2-D maps of the CUTLASS Iceland flow data (top panels) and the IMAGE UV auroral data (bottom panels), over the interval 22:2422:46 UT are presented in Fig. 6. Each map pair represents a 2-min interval (shown at the top of each column) and every other 2-min interval is shown (the exact time of each UV image is shown above each panel). Also shown on the maps are flow vectors and equipotential contours derived using the Map Potential model as discussed in Sect. 2, the locations of the five magnetometers used, and the Cluster footprint location (indicated by the unfilled black circle). At the bottom of each column the transpolar voltage, APL statistical model (Ruohoniemi and Greenwald, 1996), vector scale and IMF vector for each interval are shown. The coordinates employed in the maps are Altitude Adjusted Corrected Geomagnetic (AACGM) latitude and magnetic local time (MLT), based on the PACE coordinate system discussed by Baker and Wing (1989), with midnight at the bottom of each panel.

In Fig. 6a (22:24-22:26 UT), immediately before the onset of the BBF, we see a moderate convection pattern with a transpolar voltage of $41 \mathrm{kV}$ (compared to $57 \mathrm{kV}$ in the statistical model of Ruohoniemi and Greenwald, 1996). This is fairly typical of the interval up until this point after the IMF turned southward at $\sim 22: 16$ UT (lagged time). Some localised enhancement to the flow towards the radar is evident in the vicinity of the JAN magnetometer just poleward of a slight enhancement in auroral emissions. Figure $6 \mathrm{~b}$ (22:28-22:30 UT) shows the situation at the time of BBF "onset". In the flow data a noticeable change has occurred with fast $\left(\sim 1000 \mathrm{~m} \mathrm{~s}^{-1}\right)$ flows away from the radar now apparent just pre-midnight. This appears to have had the effect of "drawing" the nightside tip of the dusk convection cell towards dawn. There is a negligible change to the transpolar voltage, implying that the flow enhancements observed are a localised reconfiguration and not an increase in the flux throughput of the system. In the optical data, just equatorward of these fast flows is an enhanced "blob" of auroral emission peaking at an intensity of $\sim 1$ kR. In Fig. 6c (22:3222:34 UT) the pre-midnight flows have developed further into an " $\mathrm{S}$ " shape with the aurora located in the velocity shear from east to west flows (and hence, corresponding to upward field-aligned current). The transpolar voltage has also become noticeably enhanced to $49 \mathrm{kV}$, and the "blob" of aurora has also grown in size, expanding towards dusk. In Fig. 6d (22:36-22:38 UT) the flows remain much the same. The transpolar voltage has increased further still to $59 \mathrm{kV}$, while the auroral enhancements have decreased somewhat, peaking now at a modest $\sim 700 \mathrm{R}$. Figures $6 \mathrm{e}-\mathrm{f}$ show these enhanced flows and moderate aurora to persist and remain at a relatively constant level over the following $10 \mathrm{~min}$. The enhanced flows then continue for the $\sim 30$-min remainder of the substorm growth phase, before onset at $\sim 23: 20$ UT as mentioned above.

It is worth commenting on the sensitivity of the "Map Potential" transpolar voltage estimates (discussed above) to the statistical flow model employed (mentioned previously in Sect. 2). For this interval, the ratio of the number of actual data points to the number of statistical data points used in the model is approximately constant, with $\sim 400 \pm 40$ actual data points, and $\sim 540$ statistical data points. This consistency implies that variations in the voltage estimates over the interval will not be caused by variations in the influence of the statistical model. It is possible, however, that changes in the voltage may occur due to changes in which statistical model is being used at any one time. In this case, a quantitative analysis of the Map Potential results (discussed in more detail in Sect. 4.2, below) shows that whilst the statistical model does have some influence over the outcome, it does not dominate the result over the data.

\section{Discussion}

The importance of bursty bulk flows as a mechanism for the earthward transport of flux from the tail is now relatively well accepted. Early studies, such as that of Eastman et al. (1985), suggested that the plasma sheet boundary layer (PSBL) is the primary mass transport region. In that case, the flows have a large field-aligned component and are therefore not generally associated with convective transport. Baumjohann et al. (1990) showed that the occurrence rate of high-speed flows in the PSBL is only about twice that of the central plasma sheet (CPS). Taking into account that the ion density in the CPS is about three times greater than in the PSBL, they suggested that the CPS may in fact be the primary region for high-speed mass transport. Here, or more specifically, in the inner central plasma sheet (ICPS) the flows have a large fieldperpendicular component and therefore represent cross-field transport. Angelopoulos et al. (1992) studied these ICPS flows in detail and found that the high-speed bursts are embedded in longer, 10-min time scale enhanced velocity structures. It is these structures which they termed "bursty bulk flows" to indicate that, in contrast to boundary layer flows, they represent a bulk and usually convective flow of a single population.

The present study has provided simultaneous magnetospheric and ionospheric observations of a BBF-type event 
in the near-Earth ICPS. Its occurrence during relatively quiet background geomagnetic conditions has facilitated the investigation of associated flow and magnetic signatures in the ionosphere. The transient enhancement to the flow seen in the midnight sector by the CUTLASS Iceland radar is consistent with the notion of a BBF being a burst of convective transport in the tail. As mentioned above, Yeoman and Lühr (1997), Yeoman et al. (1998), and Wild and Yeoman (2000) have previously reported similar observations of transient flow features seen by CUTLASS, which they also suggested may be associated with BBF activity in the tail. These features had radar line-of-sight velocities of $\sim 500-1000 \mathrm{~m} \mathrm{~s}^{-1}$ and spatial extents of a few $\sim 100 \mathrm{~km}$, comparative to the event studied here. However, in these cases a significant azimuthal propagation was also observed, in some cases as large as $6 \mathrm{~km} \mathrm{~s}^{-1}$, which was not detected in the present study. A possible explanation for this discrepancy is that these earlier observations were made during substorm expansions and at local times displaced from midnight. Some onset theories (such as that of Shiokawa et al. (1997)) require the breaking and azimuthal redirection of the earthward plasma sheet flow, a phenomenon which has been reported by Yeoman et al. (1998) and Nakamura et al. (1999). Although there is no direct evidence of this in the present study, uncertainties in mapping ionospheric observations into the tail complicate the identification of conjugate signatures. A small area in the ionosphere maps to a large region of tail, such that the main region of flow excitation in the CUTLASS field-of-view may well map to a location considerably earthward of the Cluster spacecraft. Future work will endeavour to integrate these different observations into a simple conceptual framework using more multi-instrument observations over more local time sectors and throughout the substorm cycle.

\subsection{Field-aligned current analysis}

It was mentioned previously that the observations of Yeoman and Lühr (1997) and Wild and Yeoman (2000) were interpreted as the signatures of ionospheric Hall current vortices associated with field-aligned currents (FAC). In an attempt to visualise the pattern of FAC during this event, the curl of the velocity field (derived from the electric potential) has been determined for the interval of maximum auroral disturbance at 22:32 UT, using the technique described by McWilliams et al. (2001). This is shown alongside the corresponding auroral map in Fig. 7, with positive vorticities (red/yellow) indicating upward field-aligned current, and negative vorticities (blue) downward field-aligned current. As expected, the region of high intensity emission in the pre-midnight auroral zone corresponds to an upward field-aligned current associated with downward precipitating electrons. Poleward of this and slightly later in magnetic local time is a region of downward field-aligned current. These two regions must presumably be connected via ionospheric Pedersen currents, forming a current system not dissimilar to a typical substorm current wedge. However, the apparently low Hall conductivities involved (evidenced by the small magnetic perturbations in the presence of large flows) suggest that there is no significant Hall current component which would otherwise flow in conjunction with this Pedersen current (Cowley, 2000), hence, also explaining the lack of a typical substorm electrojet signature in the magnetometer data. In this case, the Pedersen current must therefore also be relatively small in comparison to that observed in a typical substorm electrojet.

Using the results presented in Fig. 7, it is possible to make a rough determination of the total amount of current flowing in this BBF current "wedgelet". The results imply that during the interval of maximum auroral disturbance, there is an upward field-aligned current density of $\sim 0.1 \mu \mathrm{A} \mathrm{m}^{-2} S^{-1}$ flowing over a relatively limited region of $\sim 3 \times 10^{5} \mathrm{~km}^{2}$. Assuming a non-substorm Pedersen conductivity of just a few $\mathrm{S}$ puts an upper limit on the amount of FAC of $\sim 0.1 \mathrm{MA}$. A study by Akasofu and Kamide (1976) found that, for an auroral oval at $22^{\circ}$ co-latitude (as is approximately the case in the present study) under conditions of IMF $B_{z}<-3 \mathrm{nT}$, the total current in the substorm electrojet is of the order of $1 \mathrm{MA}$, a factor of 10 greater than that suggested for the BBF. A likely explanation for this difference may lie in the size of the auroral disturbance, usually observed to be much larger during substorms, such that similar current densities will involve much larger currents overall. Also, as discussed above, the large Hall conductivities associated with substorms contribute a significant Hall component to the current in the electrojet and thus, may play a part in enhancing the current. Either way, this result implies that a "lone" BBF amounts to only a fraction of a substorm, with some further conditions being required to initiate a fully fledged expansion phase.

\subsection{Evidence for reconnection}

If, although not necessarily associated with fully developed substorms, BBFs do result from intervals of tail reconnection, then there should be measurable evidence of it. It was noted with reference to Fig. 5 above, that a flow reversal boundary in the CUTLASS data moves poleward during the $\mathrm{BBF}$ and equatorward after it. If the flow reversal boundary is representative of the open-closed field line boundary, then this would suggest that the BBF was accompanied by an interval of flux closure and hence, tail reconnection. This idea is corroborated by an analysis of the transpolar voltage below. The fact that the BBF takes place during a substorm growth phase also then explains the apparent return to an equatorward motion of the boundary after the event, which is the expected motion during intervals of dayside loading. Data from the CUTLASS Finland radar (not shown) were inspected for further evidence of growth phase behaviour. With more meridionally pointing beams than the Iceland radar, it is more suitable for investigating the equatorward motion of auroral zone scatter associated with an expanding polar cap (Lewis et al., 1997). There is some evidence of equatorward motion in the data between the time of the BBF and the onset of the substorm ( 22:30-23:20 UT), consistent with what was inferred from the Iceland data. However, there is nothing 

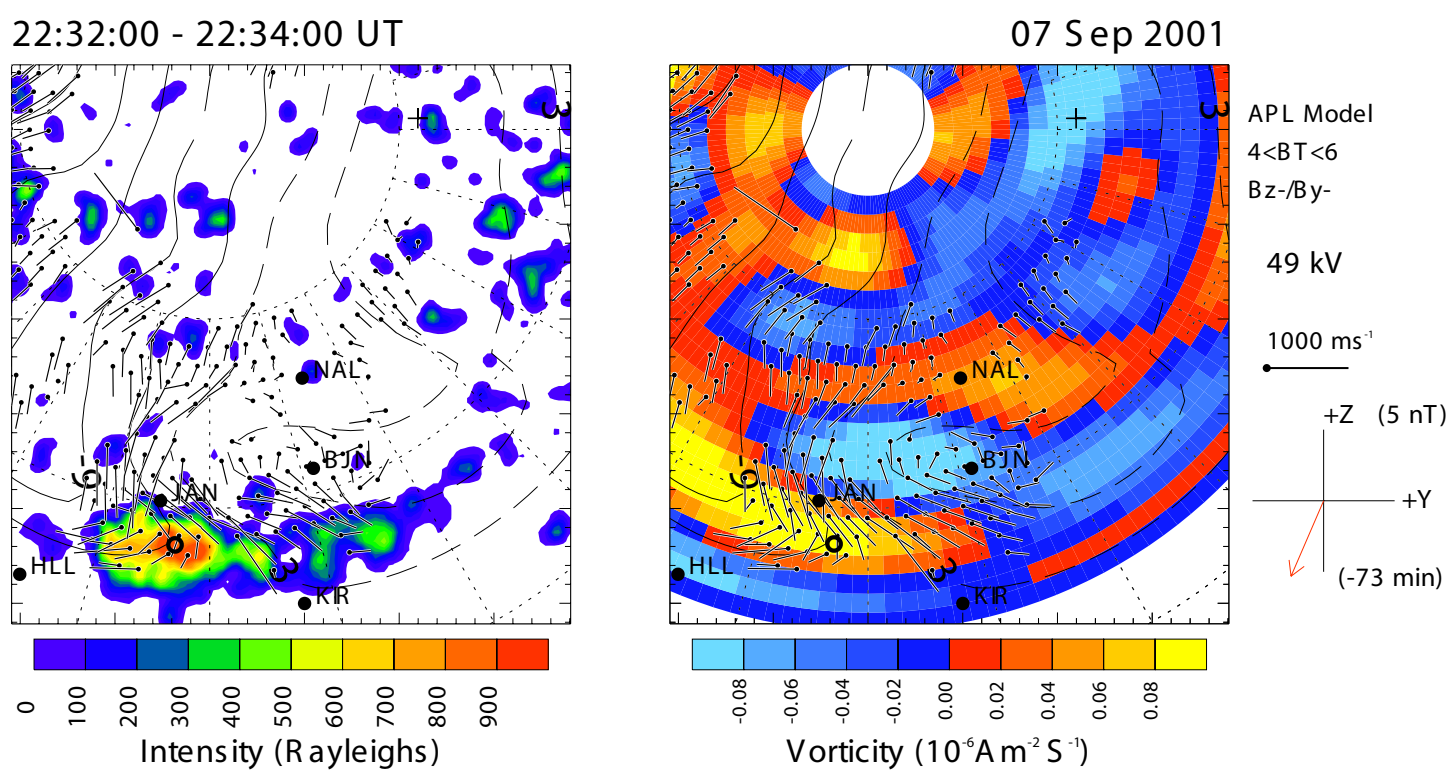

Fig. 7. IMAGE UV auroral data for the interval 22:32-22:34 UT in the same format as the maps in Fig. 6 (left-hand panel), and patterns of field-aligned currents for the same interval (right-hand panel). The field-aligned current has been estimated using the curl of the velocity field (derived from the electric potential), with positive vorticities indicating upward field-aligned current, and negative vorticities downward field-aligned current. Intensity and vorticity colour scales are indicated at the bottom of the figure.

conclusive in the scatter during the BBF concerning the nature of any boundary motion.

The main evidence for reconnection then is the enhancement in the transpolar voltage which occurs at the time of the $\mathrm{BBF}$ onset. Before the BBF, as noted above, we see voltage values slightly lower than the steady-state statistical values of Ruohoniemi and Greenwald (1996). The $\sim 20 \mathrm{kV}$ increase observed at the time of the BBF then implies an increase in flux throughput as a result of reconnection enhancements in the tail. It is relevant to note, however, that the BBF also coincides with a reorientation of the IMF to a more southward direction. This might itself explain the change in voltage, if it resulted in an increase in the reconnection rate at the dayside. Further investigation of the flow data, however, reveals that the enhancement is likely to have been due to a combination of both. Performing the Map Potential analysis with the data from the CUTLASS radars (in which the enhanced nightside flows were observed) omitted results in only a $\sim 10 \mathrm{kV}$ enhancement to the transpolar voltage, likely due to the increase in the southward component of the IMF, as suggested above. Performing the analysis with all the radar data included, but with the IMF fixed at the initial southward level, also results in a $\sim 10 \mathrm{kV}$ increase in the voltage. This suggests that both enhanced dayside driving and tail reconnection are contributing to the overall voltage increase observed. When compared to typical expansion phase associated voltage increases, Grocott et al. (2002), for example, reported about $40 \mathrm{kV}$. This result corroborates the above suggestion that whilst similar to a substorm, a BBF is a significantly smaller scale phenomenon.

\subsection{Relationship to the substorm cycle}

It was mentioned above that BBFs are often classified in terms of substorm and non-substorm events, although there remains some ambiguity as to what exactly this distinction implies. As suggested by Amm and Kauristie (2002), BBFs which occur during substorm expansive phases can differ greatly in their phenomenology from non-substorm events (compare, for example, the present study with the studies of Yeoman and Lühr (1997), Yeoman et al. (1998), and Wild and Yeoman (2000), discussed above). However, they use the term "non-substorm" to classify all events which do not occur during a substorm expansion, irrespective of the background conditions, although they stress that this is a tentative definition. This categorisation makes no distinction between so-called "quiet" intervals, where, for example, there is no evidence of the substorm cycle, and intervals of magnetospheric loading such as substorm growth phases. As suggested recently by Grocott et al. (2003) there also exist supposedly "quiet" intervals of positive IMF $B_{z}$ during which fast flows are observed in the nightside ionosphere which are apparently related to reconnection in the tail and modest loading from the dayside, yet are not accompanied by any injection or auroral signatures. Therefore, these bursts also differ phenomenologically to the BBF event discussed in this paper which occurred during a substorm growth phase. Nevertheless, at a fundamental level they must be manifestations of the same physical processes: reconnection, the closing of open flux and the convective transport of that flux earthward, away from the reconnection region. 


\section{Summary}

On 7 September 2001 the Cluster spacecraft observed evidence of a bursty bulk flow in the near-Earth central plasma sheet at a distance of $\sim 20 R_{E}$ downtail. Upstream interplanetary magnetic field data from the ACE spacecraft showed this to be an interval of southward field, consistent with one of active convection in the magnetosphere. This is confirmed by CUTLASS radar observations of plasma convection in the nightside ionosphere, in which $\sim 1000 \mathrm{~m} \mathrm{~s}^{-1}$ flow perturbations are seen in conjunction with the BBF. Optical measurements show enhanced auroral emissions from the region magnetically conjugate to the BBF, indicative of electron precipitation, yet ground magnetic records show only very small amplitude perturbations, implying very low levels of ionospheric Hall conductivity. An analysis of the pattern of field-aligned currents implied by the flow data indicates a substorm current wedge-type system. This ipoints to the occurrence of localised field dipolarisation and current disruption in the tail, but on a scale not sufficient to involve a large-scale substorm expansion. Nevertheless, this event does appear to involve tail reconnection and flux closure, as evidenced in the auroral and flow data. Clearly, the simplistic concept of substorm cycle vs. quiet times is not sufficient to fully explain the variety of mechanisms by which the magnetotail responds to varying levels of dayside loading. Investigation of similarly well observed events under differing conditions will hopefully provide further enlightenment on this ever evolving field of research.

Acknowledgements. We would like to thank the PIs of the SuperDARN radars for provision of the radar data employed in this study. The data employed were from radars funded by the research funding agencies of Canada, France, the UK, and USA. We would also like to thank Mike Ruohoniemi of the Johns Hopkins University Applied Physics Laboratory for provision of the "Map-Potential" algorithm software. For the ground magnetometer data, we thank the Finnish Meteorological Institute and its co-institutes who maintain the IMAGE magnetometer array, Børre Holmeslet of the Troms $\varnothing$ Auroral Observatory for providing the Jan Mayen magnetometer data, and Ian Mann and David Milling for the SAMNET data. SAMNET is a PPARC National Facility deployed and operated by the University of York. For provision of ACE magnetometer data we thank Norman Ness and Charles Smith of the Bartol Research Institute. We would also like to thank Kathryn McWilliams for the FAC software. AG was supported during this study by PPARC grant PPA/G/O/2001/00014, and SWHC by PPARC Senior Fellowship PPA/N/S/2000/00197. SuperDARN operations at the University of Leicester are supported by PPARC grant PPA/R/R/1997/00256. The IMAGE-FUV work was supported through SwRI subcontract 83820 at the University of California at Berkeley and by NASA under contract NAS5-96020.

Topical Editor T. Pulkkinen thanks two referees for their help in evaluating this paper.

\section{References}

Akasofu, S.-I., and Kamide, Y.: Substorm Energy, Planet. Space Sci., 24, 223-227, 1976.

Amm, O. and Kauristie, K.: Ionospheric signatures of bursty bulk flows, Surveys in Geophys., 23, 1-32, 2002.

Angelopoulos, V., Baumjohann, W., Kennel, C. F., Coroniti, F. V., Kivelson, M. G., Pellat, R., Walker, R. J., Lühr, H., and Paschmann, G.: Bursty bulk flows in the central plasma sheet, J. Geophys. Res., 97, 4027-4039, 1992.

Balogh, A., Carr, C. M., Acuña, M.-H., Dunlop, M. W., Beek, T. J., Brown, P., Fornacon, K.-H., Georgescu, E., Glassmeier, K.H., Harris, J. P., Musmann, G., Oddy, T. M., and Schwingenschuh, K.: The Cluster magnetic field investigation: Overview of in-flight performance and initial results, Ann. Geophysicae, 19, 1207-1217, 2001.

Baker, K. B. and Wing, S.: A new magnetic coordinate system for conjugate studies at high latitudes, J. Geophys. Res., 94, 91399143, 1989.

Baker, D. N., Pulkkinen, T. I., Angelopoulos, V., Baumjohann, W., and McPherron, R. L.: Neutral line model of substorms: Past results and present view, J. Geophys. Res., 101, 12 975-13010, 1996.

Baumjohann, W., Paschmann, G., and Cattell, C. A.: Average plasma properties in the central plasma sheet, J. Geophys. Res., 94, 6597-6606, 1989.

Baumjohann, W., Paschmann, G., and Lühr, H.: Characteristics of high-speed flows in the plasma sheet, J. Geophys. Res., 95, 3801-3809, 1990.

Cowley, S. W. H.: Magnetosphere-ionosphere interactions: A tutorial review, in: Magnetospheric Current Systems, 91-106, edited by Ohtani, S., Fujii, R., Hesse, M., and Lysak, R. L., AGU, Washington D. C., 2000.

de la Beaujardière, O., Lyons, L. R., Ruohoniemi, J. M., FriisChristensen, E., Danielsen, C., Rich, F. J., and Newell, P. T.: Quiet-time intensifications along the poleward boundary near midnight, J. Geophys. Res., 99, 287-298, 1994.

Eastman, T. E., Frank, L. A., and Huang, C. Y.: The boundary layers as the primary transport regions of the Earth's magnetotail, J. Geophys. Res., 90, 9541-9560, 1985.

Elphic, R. C., Lockwood, M., Cowley, S. W. H., and Sandholt, P. E.: Flux transfer events at the magnetopause and in the ionosphere, Geophys. Res. Lett., 17, 2241-2244, 1990.

Greenwald, R. A., Baker, K. B., Dudeney, J. R., Pinnock, M., Jones, T. B., Thomas, E. C., Villain, J.-P., Cerisier, J.-C., Senior, C., Hanuise, C., Hunsucker, R. D., Sofko, G., Koehler, J., Nielsen, E., Pellinen, R., Walker, A. D. M., Sato, N., and Yamagishi, H.: DARN/SuperDARN: A global view of the dynamics of highlatitude convection, Space Sci. Rev., 71, 761-796, 1995.

Grocott, A., Cowley, S. W. H., and Davies, J. A.: Comparison of ionospheric electric currents and plasma convection patterns observed during substorms, in: Proc. Fifth Internat. Conf. on Substorms, ESA SP-443, ESA, Noordwijk, The Netherlands, 295298, 2000.

Grocott, A., Cowley, S. W. H., Sigwarth, J. B., Watermann, J. F., and Yeoman, T. K.: Excitation of twin- vortex flow in the nightside high-latitude ionosphere during an isolated substorm, Ann. Geophysicae, 20, 1577-1601, 2002.

Grocott, A., Cowley, S. W. H., and Sigwarth, J. B.: Ionospheric flows and magnetic disturbance during extended intervals of northward but By-dominated IMF, Ann. Geophysicae, 21, 509538, 2003. 
Henderson, M. G., Reeves, G. D., and Murphree, J. S.: Are northsouth aligned auroral structures an ionospheric manifestation of bursty bulk flows?, Geophys. Res. Lett., 25, 3737-3740, 1998.

Hones Jr., E. W.: Transient phenomena in the magnetotail and their relation to substorms, Space Sci. Rev., 23, 393-410, 1979.

Huang, C. S., Sofko, G. J., Koustov, A. V., MacDougall, J. W., Greenwald, R. A., Ruohoniemi, J. M., Villain, J. P., Lester, M., Watermann, J., Papitashvili, V. O., and Hughes, W. J.: Long-period magnetospheric-ionospheric perturbations during northward interplanetary magnetic field, J. Geophys. Res., 106, 13 091-13 103, 2001.

Kauristie, K., Sergeev, V. A., Kubyshkina, M., Pulkkinen, T. I., Angelopoulos, V., Phan, T., Lin, R. P., and Slavin, J. A.: Ionospheric current signatures of transient plasma sheet flows, J. Geophys. Res., 105, 10 677-10 690, 2000.

Khan, H. and Cowley, S. W. H.: Observations of the response time of high latitude ionospheric convection to variations in the interplanetary magnetic field using EISCAT and IMP-8 data, Ann. Geophysicae, 17, 1306-1335, 1999.

Lewis, R. V., Freemann, M. P., Roger, A. S., Reeves, G. D., and Milling, D. K.: The electric field response to the growth phase and expansion phase onset of a small isolated substorm, Ann. Geophysicae, 15, 289-299, 1997.

Lockwood, M., Sandholt, P. E., Cowley, S. W. H., and Oguti, T.: Interplanetary field control of dayside auroral activity and the transfer of momentum across the dayside magnetopause, Planet. Space Sci., 37, 1347-1365, 1989.

Lockwood, M., Moen, J., Cowley, S. W. H., Farmer, A. D., Løvhaug, U. P., Lühr, H., and Davda, V. N.: Variability of dayside convection and motions of the cusp/cleft aurora, Geophys. Res. Lett., 20, 1011-1014, 1993.

Lühr, H., Aylward, A., Bucher, S. C., Pajunpaa, A., Pajunpaa, K., Holmboe, T., and Zalewski, S. M.: Westward moving dynamic substorm features observed with the IMAGE magnetometer network and other ground-based instruments, Ann. Geophysicae, 16, 425-440, 1998.

Lui, A. T. Y.: Current disruption in the Earth's magnetosphere: Observations and models, J. Geophys. Res., 101, 13067-13088, 1996.

Lyons, L. R., Nagai, T., Blanchard, G. T., Samson, J. C., Yamamoto, T., Mukai, T., Nishida, A., and Kokubun, S.: Association between Geotail plasma flows and auroral poleward boundary intensifications observed by CANOPUS photometers, J. Geophys. Res., 104, 4485-4500, 1999.

McComas, D. J., Bame, S. J., Barker, P., Feldman, W. C., Phillips, J. L., Riley, P., and Griffee, J. W.: Solar Wind Electron Proton Alpha Monitor (SWEPAM) for the Advanced Composition Explorer, Space Sci. Rev., 86, 563, 1998.

McWilliams, K. A., Yeoman, T. K., Sigwarth, J. B., Frank, L. A., and Brittnacher, M.: The dayside ultraviolet aurora and convection responses to a southward turning of the interplanetary magnetic field, Ann. Geophysicae, 19, 701-721, 2001.

Mende, S. B., Heetderks, H., Frey, H. U., Lampton, M., Geller, S. P., Habraken, S., Renotte, E., Jamar, C., Rochus, P., Spann, J., Fuselier, S. A., Gerard, J.-C., Gladstone, R. , Murphree, S., and Cogger, L.: Far ultraviolet imaging from the IMAGE spacecraft. 1. System design, Space Sci. Rev., 91, 243-270, 2000a.

Mende, S. B., Heetderks, H., Frey, H. U., Lampton, M., Geller, S. P., Abiad, R., Segmund, O. H. W., Tremsin, A. S., Span, J., Dougani, H., Fuselier, S. A., Magoncelli, A. L., Bumala, M. B., Murphree, S., and Trondsen, T.: Far ultraviolet imaging from the IMAGE spacecraft, 2. Wideband FUV imaging, Space Sci. Rev.,
91, 271-285, 2000b.

Milan, S. E., Jones, T. B., Lester, M., Warrington, E. M., and Reeves, G. D.: Substorm correlated absorption on a $3200 \mathrm{~km}$ trans-auroral HF propagation path, Ann. Geophysicae, 14, 182190, 1996.

Milan, S. E., Lester, M., Cowley, S. W. H., and Brittnacher, M.: Convection and auroral response to a southward turning of the IMF: Polar UVI, CUTLASS, and IMAGE signatures of transient magnetic flux transfer at the magnetopause, J. Geophys. Res., 105, 15 741-15 755, 2000.

Moen, J., Sandholt, P. E., Lockwood, M., Denig, W. F., Løvhaug, U. P., Lybekk, B., Egeland, A., Opsvik, D., and Friis-Christensen, E.: Events of enhanced convection and related dayside auroral activity, J. Geophys. Res., 100, 23 917-23 934, 1995.

Nakamura, R., Haerendel, G., Baumjohann, W., Vaivads, A., Kucharek, H., Klecker, B., Georgescu, E., Birn, J., Kistler, L. M., Mukai, T., Kokubun, S., Eglitis, P., Frank, L. A., Sigwarth, J. B.: Substorm observations in the early morning sector with EquatorS and Geotail, Ann. Geophysicae, 17, 1602-1610, 1999.

Nakamura, R., Baumjohann, W., Brittnacher, M., Sergeev, V. A., et al.: Flow bursts and auroral activations: Onset timing and foot point location, J. Geophys. Res., 106, 10 777-10 789, 2001.

Neudegg, D. A., Yeoman, T. K., Cowley, S. W. H., Provan, G., et al.: A flux transfer event observed at the magnetopause by the Equator-S spacecraft and in the ionosphere by the CUTLASS HF radar, Ann. Geophysicae, 17, 707-711, 1999.

Neudegg, D. A., Cowley, S. W. H., Milan, S. E., Yeoman, T. K., Lester, M., et al.: A survey of magnetopause FTEs and associated flow bursts in the polar ionosphere, Ann. Geophysicae, 18, 416435, 2000.

Opgenoorth, H. J. and Pellinen, R. J. : The reaction of the global convection electrojets to the onset and expansion of the substorm current wedge, in: Substorms-4, edited by Kokobun, S. and Kamide, Y., Terra Sci. Publ. Co., Tokyo, 663-668, 1998.

Pinnock, M., Rodger, A. S., Dudeney, J. R., Baker, K. B., Greenwald, R. A., and Greenspan, M.: Observations of an enhanced convection channel in the cusp ionosphere, J. Geophys. Res., 98, 3767-3776, 1993.

Pinnock, M., Rodger, A. S., Dudeney, J. R., Rich, F., and Baker, K. B.: High temporal and spatial observations of the ionospheric cusp, Ann. Geophysicae, 13, 919-925, 1995.

Provan, G., Yeoman, T. K., and Milan, S. E.: CUTLASS Finland radar observations of the ionospheric signatures of flux transfer events and the resulting plasma flows, Ann. Geophysicae, 16, 1411-1422, 1998.

Rème, H., Aoustin, C., Bosqued, J. M., Dandouras, I., et al.: First multispacecraft ion measurements in and near the Earth's magnetosphere with the identical Cluster ion spectrometry (CIS) experiment, Ann. Geophysicae, 19, 1303-1354, 2001.

Russell, C. T. and McPherron, R. L.: The magnetotail and substorms, Space Sci. Rev., 15, 205-266, 1973.

Ruohoniemi, J. M. and Greenwald, R. A.: Statistical patterns of high-latitude convection obtained from Goose Bay HF radar observations, J. Geophys. Res., 101, 21 743-21 763, 1996.

Ruohoniemi, J. M. and Baker, K. B.: Large-scale imaging of highlatitude convection with Super Dual Auroral Radar Network HF radar observations, J. Geophys. Res., 103, 20 797-20 811, 1998.

Sergeev, V. A., Aulamo, O. A., Pellinen, R. J., Vallinkoski, M. K., et al.: Non-substorm transient injection events in the ionosphere and magnetosphere, Planet. Space Sci., 38, 231-239, 1990.

Shiokawa, K., Baumjohann, W., and Haerendel, G.: Breaking of high-speed flows in the near-Earth tail, Geophys. Res. Lett., 24, 
1179-1182, 1997.

Smith, C. W., Acuña, M. H., Burlaga, L., et al.: The ACE Magnetic Field Experiment, Space Sci. Rev., 86, 613-622, 1999.

Stone, E. C., Frandsen, A. M., Mewaldt, R. A., Christian, E. R., et al.: The Advanced Composition Explorer, Space Sci. Rev., 86, 1-22, 1998.

Tsyganenko, N. A.: Modeling the Earth's magnetospheric magnetic field confined within a realistic magnetopause, J. Geophys. Res., 100, 5599-5612, 1995.

Walker, A. D. M., Baker, K. B., Pinnock, M., Dudeney, J. R., and Rash, J. P. S.: Radar observations of magnetospheric activity during extremely quiet solar wind conditions, J. Geophys. Res., doi: 10.129/2001JA000063, 2002.

Walker, A. D. M., Pinnock, M., Baker, K. B., Dudeney, J. R., and Rash, J. P. S.: Strong flow bursts in the nightside ionosphere during extremely quiet solar wind conditions, Geophys. Res. Lett., 25, 881-884, 1998.
Wild, J. A. and Yeoman, T. K.: CUTLASS HF radar observations of high-latitude azimuthally propagating vertical currents in the nightside ionosphere during magnetospheric substorms, Ann. Geophysicae, 18, 640-652, 2000.

Yeoman, T. K., Milling, D. K., and Orr, D.: Pi2 pulsation polarisation patterns on the U.K. Sub- auroral Magnetometer Network (SAMNET), Planet Space Sci., 38, 589-602, 1990.

Yeoman, T. K. and Lühr, H.: CUTLASS/IMAGE observations of high-latitude convection features during substorms, Ann. Geophysicae, 15, 692-702, 1997.

Yeoman, T. K., Mukai, T., and Yamamoto, T.: Simultaneous ionospheric and magnetospheric observations of azimuthally propagating transient features during substorms, Ann. Geophysicae, 16, 754-763, 1998.

Yeoman, T. K., Davies, J. A., Wade, N. M., Provan, G., and Milan, S. E.: Combined CUTLASS, EISCAT and ESR observations of ionospheric plasma flows at the onset of an isolated substorm, Ann. Geophysicae, 18, 1073-1087, 2000. 